\title{
Investigation on trophic state index by artificial neural networks (case study: Dez Dam of Iran)
}

\author{
H. Saghi · L. Karimi · A. H. Javid
}

Received: 29 April 2013/Accepted: 18 February 2014/Published online: 9 April 2014

(C) The Author(s) 2014. This article is published with open access at Springerlink.com

\begin{abstract}
Dam construction and surface runoff control is one of the most common approaches for water-needs supply of human societies. However, the increasing development of social activities and hence the subsequent increase in environmental pollutants leads to deterioration of water quality in dam reservoirs and eutrophication process could be intensified. So, the water quality of reservoirs is now one of the key factors in operation and water quality management of reservoirs. Hence, maintaining the quality of the stored water and identification and examination of changes along time has been a constant concern of humans that involves the water authorities. Traditionally, empirical trophic state indices of dam reservoirs often defined based on changes in concentration of effective factors (nutrients) and its consequences (increase in chlorophyll $a$ ), have been used as an efficient tool in the definition of dam reservoirs quality. In recent years, modeling techniques such as artificial neural networks have enhanced the prediction capability and the accuracy of these studies. In this study, artificial neural networks have been applied to analyze eutrophication process in the Dez Dam reservoir in Iran. In this paper, feed forward neural network with one input layer, one hidden layer and one output layer was
\end{abstract}

H. Saghi $(\bowtie)$

Department of Civil Engineering, Hakim Sabzevari University,

Sabzevar, Iran

e-mail: h.saghi@hsu.ac.ir

L. Karimi

Department of Environment and Energy, Science and Research Branch, Islamic Azad University, Tehran, Iran

A. H. Javid

Department of Marine Science and Technology, Science and Research Branch, Islamic Azad University, Tehran, Iran applied using MATLAB neural network toolbox for trophic state index (TSI) analysis in the Dez Dam reservoir. The input data of this network are effective parameters in the eutrophication: nitrogen cycle parameters and phosphorous cycle parameters and parameters that will be changed by eutrophication: $\mathrm{Chl} a, \mathrm{SD}, \mathrm{DO}$ and the output data is TSI. Based on the results from estimation of modified Carlson trophic state index, Dez Dam reservoir is considered to be eutrophic in the early July to mid-November and would be mesotrophic with decrease in temperature. Therefore, a decrease in water quality of the dam reservoir during the warm seasons is expectable. The results indicated that artificial neural network (ANN) is a suitable tool for quality modeling of reservoir of dam and increment and decrement of nutrients in trend of eutrophication. Therefore, ANN is a suitable tool for quality modeling of reservoir of dam.

Keywords Trophic state index $\cdot$ Artificial neural networks · Dez Dam

\section{Introduction}

Eutrophication and algal blooms are serious problems in many lakes and reservoirs (Cüneyt Karul 2000). Combating the adverse effects of eutrophication is often very costly, and in some cases it is impossible to restore the lake to its initial state (Ryding 1989). Increased levels of nutrients, such as total nitrogen (TN) and total phosphorus (TP) through agricultural pollution, industrial wastewater or sewage discharge, coupled with high temperature, commonly enhanced the growth of algae, and sometimes even results in excess algal blooms (Borchardt 1996; Codd et al. 2005; Kosten 2012), particularly eutrophication. Hence, a detailed understanding 
Table 1 Eutrophication state of dam reservoir based on Carlson index

\begin{tabular}{lllll}
\hline Trophic state & $\mathrm{SD}(\mathrm{m})$ & $\mathrm{Chl} a(\mu \mathrm{g} / \mathrm{l})$ & $\mathrm{TP}(\mu \mathrm{g} / \mathrm{l})$ & $\mathrm{TSI}$ \\
\hline Oligotrophic & $>40$ & $<2.6$ & $<12$ & $<40$ \\
Mesotrophic & $20-40$ & $2.6-7.2$ & $12-24$ & $40-50$ \\
Eutrophic & $0.5-20$ & $7.22-55.5$ & $24-96$ & $50-70$ \\
Hypereutrophic & $<0.5$ & $>55.5$ & $>96$ & $>70$ \\
\hline
\end{tabular}

of the changes in water quality of dam and reservoirs is very important. In the recent years, trophic state indices have been used for this purpose. Since the 1960s, attempts have been made to evaluate the trophic status of lakes by quantitatively applying single-variable trophic indices and multi-parameter approaches (Xu 2011). The relatively simple single-variable trophic state criteria represent only subjective judgments, and may be limited spatially (Therriault and Platt 1978; Chapra 1983; Boyle et al. 1990; Danilov and Ekelund 1999). Comparatively, multi-parameter approaches are more robust than single-variable trophic indices, because of the multidimensional nature of the eutrophication phenomenon in water bodies (Carlson 1977; Cruzado 1987; $\mathrm{Xu}$ 2008). Moreover, it would be difficult to describe the continuous changes of a lake's trophic state or to study the eutrophication mechanism quantitatively, using descriptive classifications for lake trophic states such as oligotrophic, mesotrophic and eutrophic (Carlson 1977; Yoshimi 1987; Xu 2008). The trophic state indexes (TSI), especially the Carlson-type TSIs, have been proposed by some researchers in order to characterize the multidimensional nature of eutrophication and to effectively eliminate the subjective labeling associated with the use of oligotrophic, mesotrophic and eutrophic states as indicators (e.g., Carlson 1977; Walker 1979; Porcella et al. 1980; Swanson 1998; Aizaki et al. 1981; Jin et al. 1990; Xu 2008). These TSIs offer a 0-100 scale providing continuous numerical classes of lake trophic states and a rigorous foundation for quantitative studies of the underlying causes of eutrophication. TSI method has been proved as the most suitable and acceptable method for trophic classifications of lakes (Xu 2008). Carlson Trophic state index expressed by empirical Eqs. (1-3) and results were analyzed based on Table 1 as follows:

$$
\begin{aligned}
\mathrm{TSI} & =60-14.43 \mathrm{LN}(\mathrm{SD}) \\
\mathrm{TSI} & =3056+9.81 \mathrm{LN}(\mathrm{Chl} \mathrm{a}) \\
\mathrm{TSI} & =4.14+14.43 \mathrm{LN}(\mathrm{TP}) .
\end{aligned}
$$

In the recent years, several studies have analyzed the trophic state of dam reservoirs, using the modified or unmodified Carlson index. For example, the nutritional condition of 19 lakes in the north east of Poland has been studied based on changes in phosphorus and utilizes Carlson index. On the other hand, the Carlson index with no change has been used for trophic state process (Kiersztyn 2002). In a study by North Dakota Department of Health Division of Water Quality, the Carlson index with no change has been used in order to review the maximum amount of total maximum daily load (TMDL) of nutrients into the Northgate Dam in the Dakota (Nutrient and Dissolved Oxygen TMDLs for Northgate Dam in Burke County, North Dakota 2006). In 2009, the trophic state of Shapur Dam reservoir in Pakistan has been studied based on Carlson index (Janjua et al. 2009). Hence, many studies have tried to modify this index in order to provide better results using other parameters. For example, Mandaville used the changes in the concentrations of macrophytes with the Carlson index to evaluate the trophic state of shallow reservoirs. This research states that the results have an appropriate and acceptable accuracy compared with unchanged Carlson index (Mandaville 2000, 2005). In 2010, the Carlson index with a little change has been used to examine the trophic state of Castanhão Dam reservoir as a large dam in Brazil. This study has used the index introduced by Carlson (1977) and TSI introduced by Lamparelli in 2004. It is mentioned that Lamparelli in 2004 has changed the Carlson index and finally the boundary of lakes classification in terms of trophic state, by using the changes in the empirical coefficients in the TSI estimation. Johns (1998) introduced Indiana trophic state index, the new version of Carlson index, using DO, TN and SD parameters (Johns 1998). This index was accepted by a number of researchers in the water industry and a lot of research work were done based on it. For example, Sharma et al. (2010) used this index for trophic state analysis of Mansi Ganga Dam reservoir in India, and indicated that this index can be used as a selective index for trophic state analysis of dam reservoirs in India (Sharma et al. 2010). Kratzer and Brezonik (1981) have used the modified Carlson index for eutrophication state analysis in dams located in America (Florida State), using analysis of total nitrogen parameter (TN) In addition to the Carlson index and considering TN/TP ratio in the estimations. This modification can be the best and most widely used index of modified Carlson index. Florida modified index was introduced as a permanent and selective method for trophic state analysis of dam reservoirs in this state (Florida Department of Environmental Protection 2008). Equations (4-12) present the modified TSI index (Florida Department of Environmental Protection 1996). 
Fig. 1 Geographic location and population centers of Dez Dam

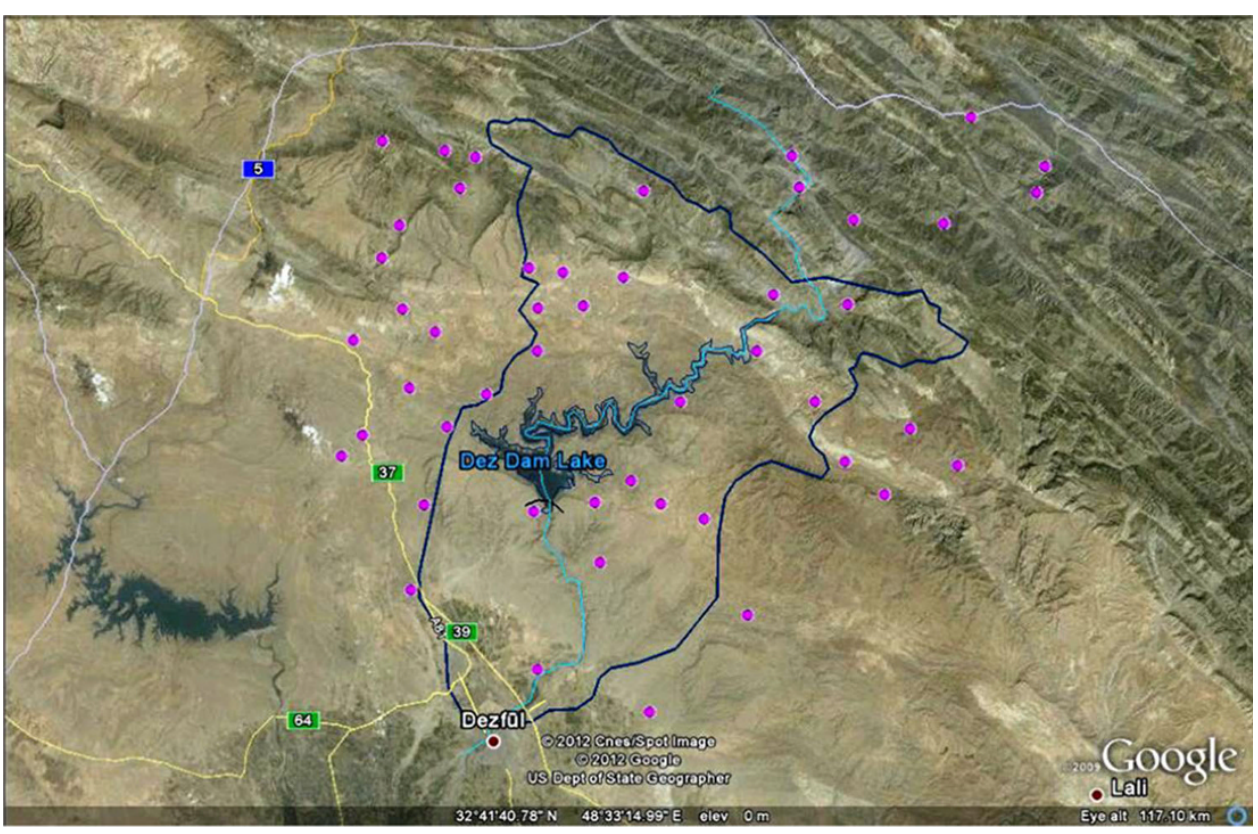

$$
\begin{aligned}
& \text { TSI }(\text { Chl a })=16.8+[14.4 * \mathrm{LN}(\mathrm{Chl} \mathrm{a})] \\
& \begin{aligned}
\text { TSI }(\mathrm{TN})= & 56+[19.8 * \mathrm{LN}(\mathrm{TN})] \\
\text { TSI }(\mathrm{TN} 2)= & 10 \\
& +[5.96+2.15 * \mathrm{LN}(\mathrm{TN}+0.0001)]
\end{aligned}
\end{aligned}
$$

$$
\begin{aligned}
& \text { TSI }(\mathrm{TP})=[18.6 * \mathrm{LN}(\mathrm{TP} * 1,000)]-18.4 \\
& \mathrm{TSI}(\mathrm{TP} 2)=10 *[2.36 * \mathrm{LN}(\mathrm{TP} * 1000)-2.38] \\
& \text { If } \mathrm{TN} / \mathrm{TP}>30 \text { then TSI }=\mathrm{TSI}(\mathrm{TP} 2) \\
& \text { If } \mathrm{TN} / \mathrm{TP}<10 \text { then TSI }=\mathrm{TSI}(\mathrm{TN} 2) \\
& \text { If } 10<\mathrm{TN} / \mathrm{TP}<30 \text { then TSI }(\mathrm{NUTR}) \\
& \quad=[\mathrm{TSI}(\mathrm{TP})+\mathrm{TSI}(\mathrm{TN})] / 2 \\
& \mathrm{TSI}=[\mathrm{TSI}(\mathrm{Chl} \mathrm{a})+\mathrm{TSI}(\mathrm{NUTR})] / 2 .
\end{aligned}
$$

In the recent years, by introducing numerical modeling to the field of dam reservoirs management, eutrophication state could be done with more precision and future assessment possibility. Artificial neural networks are one of these methods that have been welcomed by most experts. In the quality management of dam reservoirs, artificial neural networks have been used in the algal blooms prediction, eutrophication and dissolved oxygen changes. However, TSI analysis has been less applied in this domain. In this article, TSI process, suggested by Florida Department of Environmental Protection, is analyzed for Dez Dam reservoir in Iran using artificial neural networks.

\section{Materials and methods}

Study area

Dez Dam water basin is located in the Zagros Mountains, within the longitude and latitude of $48^{\circ} 31^{\prime}-$ $49^{\circ} 35^{\prime} \mathrm{E}$ and $33^{\circ} 39^{\prime}-32^{\circ} 40^{\prime} \mathrm{N}$. This water basin area is located in the Khuzestan Province, $25 \mathrm{~km}$ northeast of Dezful and $23 \mathrm{~km}$ northeast of Andimeshk and in the Dez-Karun water basin area. This dam is the largest dam in the Middle East (at the time of construction, 1957) and the third largest dam in the world. It also has an important role in the water-need supply in Khuzestan Province (Moshanir Consulting Engineering Company 2007). Figure 1 shows the Geographic location and population centers of this water basin.

The study was done based on the results of sampling studies and environmental tests of the second power plant of Dez Dam in the period of 2008-2007. Sampling was performed for 1 year at two stations and from different depths of the reservoir.

The stations where sampling was done are as follows:

- First station was at the back of dam crest at longitude of $48^{\circ} 27^{\prime} 45^{\prime \prime}$ and latitude of $32^{\circ} 36^{\prime} 27^{\prime \prime}$

- Second station was in front of the Pamenar village at longitude of $48^{\circ} 27^{\prime} 13^{\prime \prime}$ and latitude of $32^{\circ} 38^{\prime} 36^{\prime \prime}$.

The parameters are summarized in Table 2 . 
Table 2 Parameter description used in the research

\begin{tabular}{|c|c|c|c|c|c|c|c|c|}
\hline Parameter & $\mathrm{pH}$ & DO & EC & $\mathrm{NH}_{4}^{+}$ & $\mathrm{NO}_{3}^{-}$ & TSS & TDS & \\
\hline Description & $\mathrm{pH}$ & Dissolved oxygen & Electrical conductivity & Ammonia & Nitrate & Total suspended solids & Total & dissolved solids \\
\hline Parameter & $\mathrm{PO}_{4}{ }^{3-}$ & $\mathrm{Fe}_{3}^{+}$TIC & TOC & \multicolumn{2}{|c|}{$\mathrm{BOD}_{5}$} & $\mathrm{TP}\left(\mathrm{PO}_{4}{ }^{3}\right.$ & & $\mathrm{TN}\left(\mathrm{NO}_{3}{ }^{-}\right)$ \\
\hline
\end{tabular}

\section{Artificial neural networks (ANN)}

The concept of artificial neurons was first introduced in 1943 (McCulloch and Pitts 1943). ANNs constitute an information-processing paradigm that is inspired by biological neural systems (Haykin 1999). Researching the application of ANNs has been intensified since the introduction of the back propagation (BP) training algorithm for feed forward ANNs in 1986 (Rumelhart et al. 1986). Feed forward neural networks propagate data linearly from input to output and they are the most popular and most widely used models in many practical applications. Artificial neural networks are often made of an input layer, one or more hidden layers, and an output layer as Fig. 2.

The general formula for the data transfer from the input layer to the output layer is defined by Eq. (13).

$$
Y_{i}=\sum_{j=1}^{R} W_{j} X_{j}+b,
$$

where $R$ is the number of neurons in the last layer, $X_{i(i=1, R)}$ are the input data from neurons in the last layer, $W_{i(i=1, R)}$ are the weights of $X_{i}$ neurons and $b$ is the bias.

The main differences between the various types of ANNs include network architecture consisting of hidden layer number, the number of neurons in each layer and activation function used in each neuron and training methods. There are different activation functions such as linear, sigmoid and tangent hyperbolic functions presented as follows, respectively (Caudill and Butler 1992):

$f(n)=n$

$f(n)=\frac{1}{1+e^{-n}}$
Fig. 2 Feed forward neural network with one hidden layer

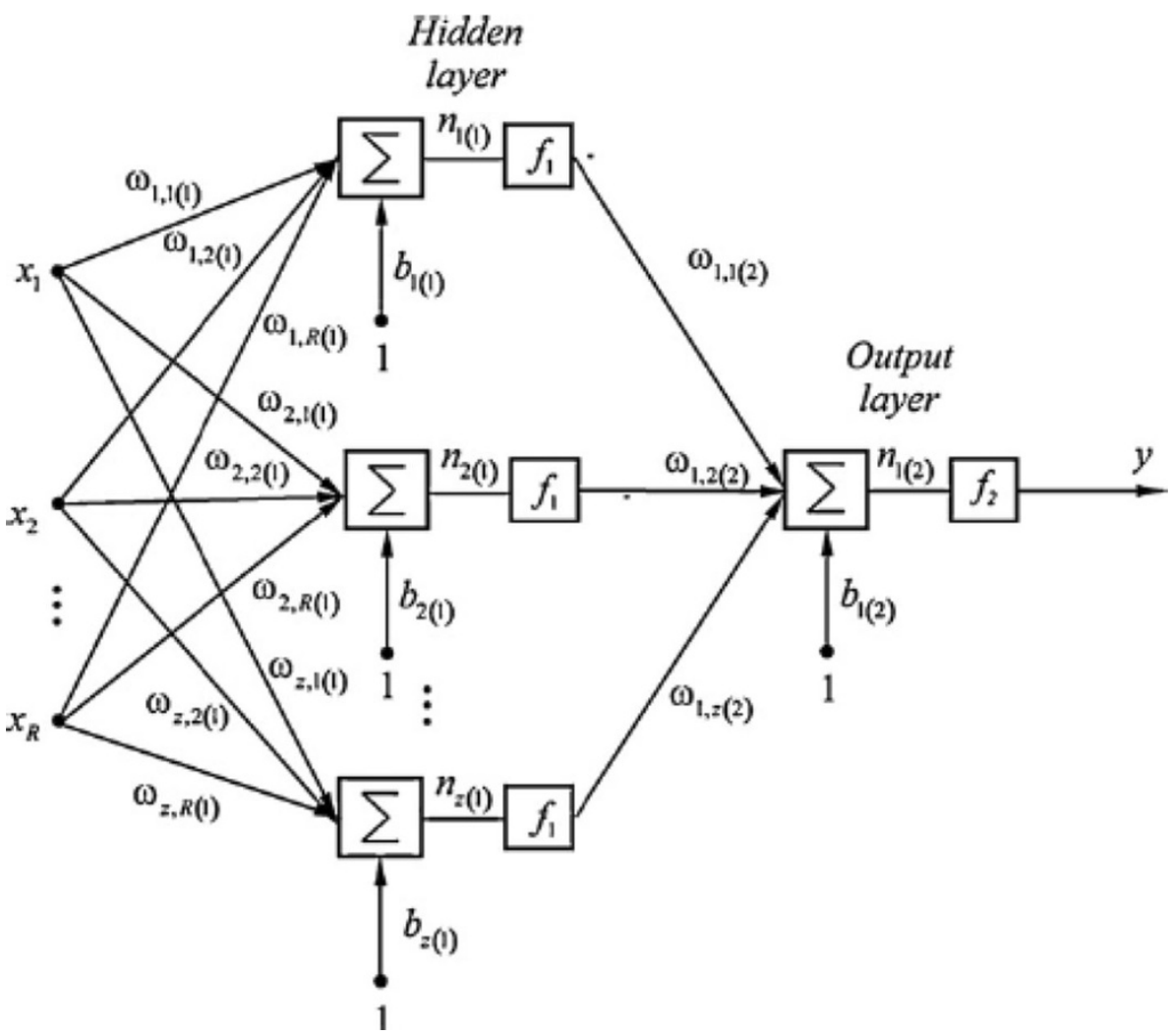


$f(n)=\frac{1-e^{-n}}{1+e^{-n}}$.

\section{Application of artificial neural network for reservoirs quality management}

Cüneyt Karul (1999) introduced artificial neural networks as a powerful tool in the dam reservoirs management and used the method in the quality and quantity management of reservoirs. Study of input flow amount into the reservoir (Ichiyanagi 1995), hydraulic specifications (Salmasi 2010) and sediments estimation (Jothiprakash et al. 2009) are samples of neural networks application in the quality and quantity management of dam reservoirs. Many research works using artificial neural networks has been done on quality topic especially on eutrophication process of dam reservoirs. Cüneyt Karul (1999) used artificial neural networks for chlorophyll $a$ modeling as a TSI for the Keban Dam reservoir in Turkey. In this study, we used an artificial neural network made of three layers: an input layer, an output layer, and a hidden layer with progressive operation. Input data includes $\mathrm{PO}_{4}, \mathrm{NO}_{3}$, alkalinity, TSS, $\mathrm{pH}$, temperature, electrical conductivity, dissolved oxygen and Secchi disk. Chlorophyll $a$ concentration consisted of the output layer of this network and communication between layers is done by the sigmoid function. This structure has an appropriate accuracy for evaluating eutrophication behavior of dam reservoir (Cüneyt Karul 1999). Cüneyt Karul (2000) studied the Mogan and Eymir dams by theories used in the neural network of Keban Dam, and finally compared the obtained results for these three dams. According to this research, results obtained from Mogan and Eymir dams with more continues water flow have a coefficient of determination of 0.95 (Cüneyt Karul 2000).

Mark et al. (2001) used artificial neural network for eutrophication modeling in the Burrinjuck Dam reservoir in Australia and compared the results with those of SALMO $^{1}$ model. The comparison indicates that, both analyzed models are capable for assessing the quality changes in the dam reservoir; however, they are different in terms of the accuracy of short- and long-term results (Mark et al. 2001). Lee et al. (2003) used this method for Tolo Dam in Hong Kong in addition to challenge the previous studies on using artificial neural networks in modeling eutrophication phenomena in the dam reservoirs. Joseph thinks that, most studies up to that time had no appropriate processing on the data and virtually all available parameters have been used as input. Hence, in their study, the input data have been chosen with greater sensitivity and precision. Joseph in this study used three-layer back propagation neural network with transfer function sigmoid

\footnotetext{
${ }^{1}$ Simulation by means of an Analytical Lake Model.
}

(Lee et al. 2003). Muhittin Aslan (2008) simulated Eymir Dam in Turkey using artificial neural networks and fuzzy inference systems and compared the obtained data. The results of this study stated that the output data of neural network, compared with fuzzy method, is significantly more accurate and more acceptable (Muhittin Aslan 2008). Jan-Tai Kuoa (2007) used artificial neural network for modeling eutrophication process of Te-Chi Dam reservoir. In this study, contrary to the previous studies, the chlorophyll $a$ is not considered as a TSI and instead, it has been used from Carlson index. Jan-Tai Kuoa editing four neural networks, has simulated the main parameters such as DO, $\mathrm{SD}, \mathrm{TP}$, and the chlorophyll $a$, and replaced the results in the Carlson linear equation. Finally, the Carlson index was estimated as eutrophication state of dam reservoir (Jan-Tai Kuoa 2007).

The main point in the all previous research works is acceptable output result of artificial neural network that introduced this method as a powerful tool for qualitative modeling of dam reservoirs.

\section{Artificial neural networks application}

In this paper, feed forward neural network with one input layer, one hidden layer and one output layer was applied using MATLAB neural network toolbox for TSI analysis in the Dez Dam reservoir (Fig. 3). The input data of this network are effective parameters in the eutrophication: nitrogen cycle parameters $\left(\mathrm{TN}, \mathrm{NO}_{3}, \mathrm{NH}_{4}\right)$ and phosphorous cycle parameters $\left(\mathrm{TP}, \mathrm{PO}_{4}\right)$ and parameters that will

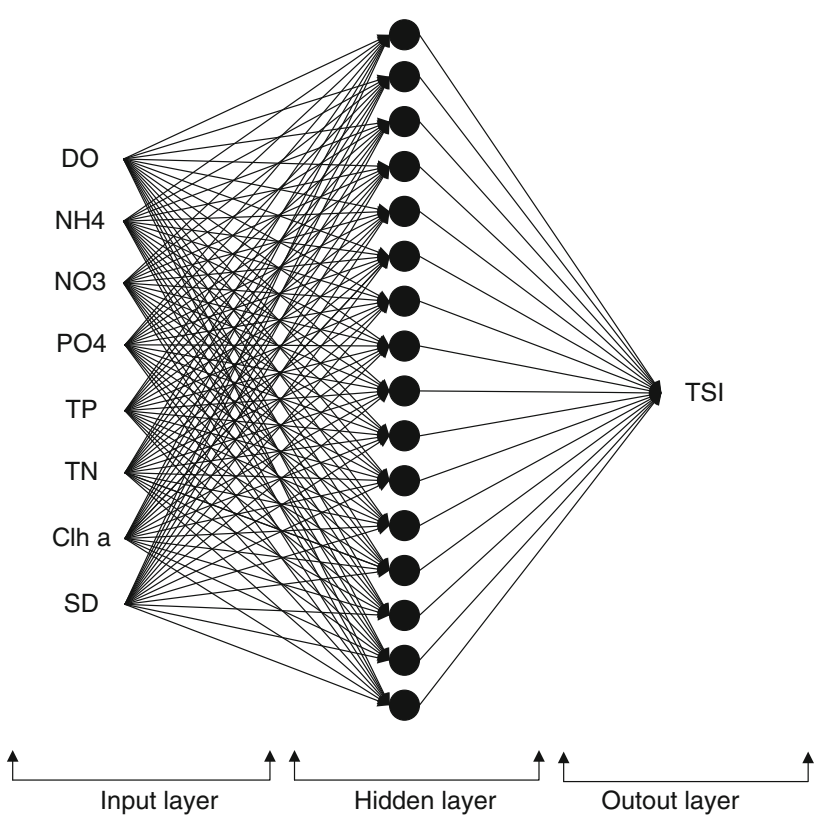

Fig. 3 Schematic primary structure of artificial neural network of Dez Dam reservoir 
be change by eutrophication: $\mathrm{Chl} a, \mathrm{SD}, \mathrm{DO}$ and the output data is TSI.

Before training and validation, scaled the inputs and targets were scaled using normalized equation such that the data always fall within a specified range:

$X_{n}=\left(Y_{\max }-Y_{\min }\right)\left(\frac{X-X_{\min }}{X_{\max }-X_{\min }}\right)-Y_{\min }$

where $X$ is the data value, $X_{n}$ is the normalized data value, $X_{\max }$ and $X_{\min }$ are the maximum and minimum values of all the obtained data during the training period and $Y_{\max }$ and
$Y_{\min }$ are maximum and minimum values in the range of $(0.05,0.95)$.

\section{Results}

Trophic state index in the Dez Dam reservoir

Trophic state index is estimated by using Eqs. (4-12) and the results are presented in Tables 3 and 4 and Fig. 4.

Table 3 Total trophic state index and effective parameters at the station 1

\begin{tabular}{lllllllllllll}
\hline October & September & August & July & June & May & April & March & February & January & December & November & TSI \\
\hline 63.4 & 65.8 & 64.3 & 59.9 & 56.8 & 52.6 & 53.7 & 53.7 & 58.4 & 59.2 & 68.8 & 69.2 & TSI Chl $a$ \\
50.3 & 52.2 & 52.8 & 53.2 & 53.1 & 52.1 & 51.1 & 49.4 & 46.7 & 46.5 & 47.4 & 49.2 & TSI 1 TN \\
53.4 & 55.5 & 56.1 & 56.6 & 56.3 & 55.3 & 54.2 & 52.4 & 49.2 & 49.4 & 50.3 & 52.2 & TSI 2 TN \\
46.1 & 50.7 & 49.2 & 44.8 & 35.3 & 33.2 & 27.8 & 29.3 & 30.7 & 33.4 & 48.8 & 51 & TSI 1 TP \\
58 & 63.8 & 62.1 & 56.4 & 44.4 & 41.7 & 34.8 & 36.8 & 38.5 & 41.9 & 61.4 & 64.2 & TSI 2 TP \\
48.2 & 51.4 & 51.1 & 49.1 & 44.4 & 41.6 & 34.8 & 36.7 & 38.5 & 41.9 & 48.3 & 50.1 & NUTR TSI \\
55.8 & 58.61 & 57.64 & 56.18 & 50.57 & 47.11 & 44.29 & 45.23 & 48.45 & 50.55 & 58.45 & 59.63 &
\end{tabular}

Table 4 Total trophic state index and effective parameters at the station 2

\begin{tabular}{lllllllllllll}
\hline October & September & August & July & June & May & April & March & February & January & December & November & Parameters \\
\hline 62.7 & 60.6 & 63.1 & 61.9 & 60.1 & 52.6 & 55.8 & 52.6 & 59.2 & 58.4 & 69.2 & 68.8 & TSI Chl $a$ \\
46.8 & 49.2 & 50.6 & 51.6 & 51.6 & 51.6 & 50.9 & 48.1 & 44.3 & 45.1 & 46.8 & 47.5 & TSI 1 TN \\
49.6 & 52.3 & 53.7 & 54.8 & 54.8 & 54.8 & 54.1 & 50.9 & 46.9 & 47.7 & 49.6 & 50.4 & TSI 2 TN \\
41.9 & 42.2 & 41.5 & 39.1 & 35.4 & 22.5 & 19.9 & 24.4 & 30.7 & 39.9 & 48.8 & 54.4 & TSI 1 TP \\
52.8 & 53.1 & 52.2 & 49.1 & 44.4 & 28.1 & 24.8 & 30.5 & 38.5 & 50.2 & 61.4 & 68.5 & TSI 2 TP \\
44.4 & 45.7 & 52.2 & 49.1 & 44.4 & 28.1 & 24.8 & 30.5 & 38.5 & 42.5 & 47.8 & 50.9 & NUTR TSI \\
54.18 & 57.55 & 57.29 & 55.52 & 52.23 & 43.2 & 40.29 & 41.56 & 48.84 & 53.5 & 57.3 & 59.87 & TSI \\
\hline
\end{tabular}

Fig. 4 Eutrophication state of Dez Dam reservoir at the stations 1 and 2

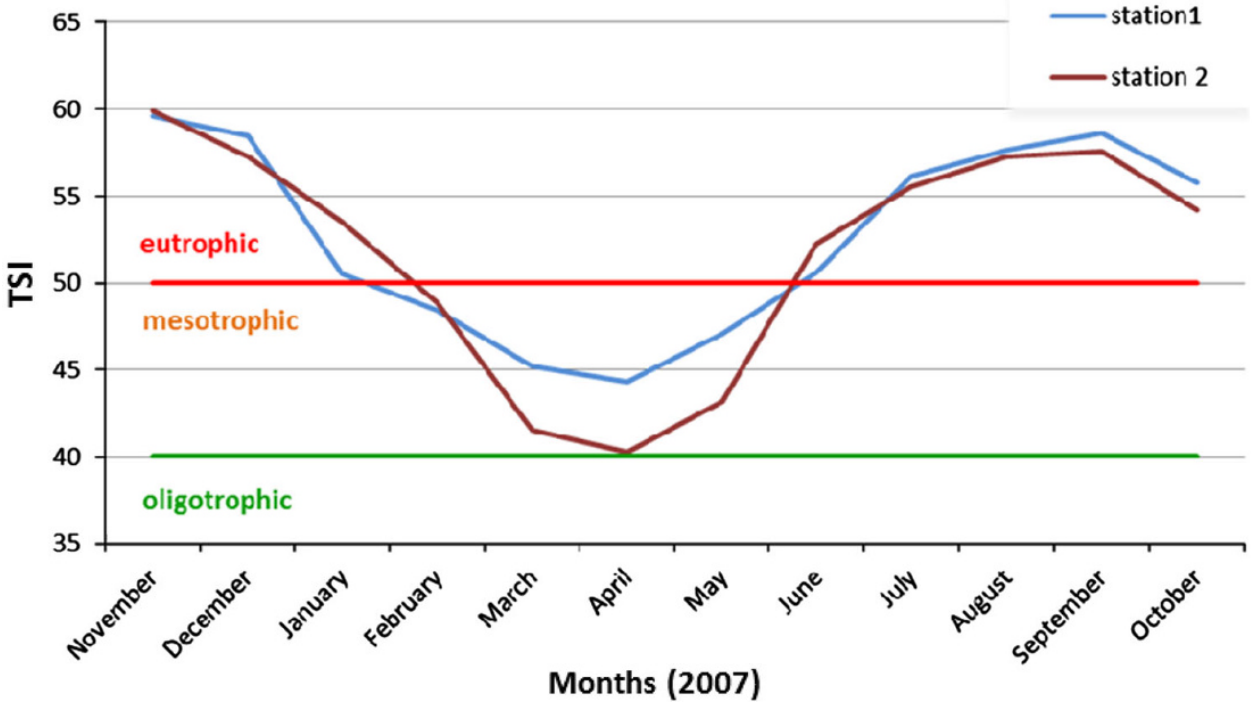


Based on the results from Tables 3 and 4 and Fig. 4, Dez Dam reservoir is considered to be eutrophic in the early July to mid-November and would be mesotrophic by decrease in temperature. Therefore, a decrease in water quality of the dam reservoir during the warm seasons is expectable.

Trophic state index modeling using artificial neural network

In order to achieve the appropriate structure of artificial neural network that indicates the eutrophication state of Dez Dam reservoir, first basic structure (Fig. 3) was developed with different modes of composition of functions. Also, number of hidden layers was trained and simulated by MATLAB software. Based on this, nine possible arrangements for the transfer and activity functions (tangent sigmoid, log sigmoid and linear) and 20 possible arrangements for the number of hidden layer cells (10-30) in total of 180 different artificial neural network structures were investigated. Errors MSE (mean squared error), SAE (sum of absolute errors) and SSE (sum squared error) were estimated on output data of total analyzed structures corresponding to Eqs. (18-20):

$\operatorname{MSE}=\frac{1}{N} \sum_{i=1}^{N}\left(Y-Y_{i}\right)$

$\mathrm{SAE}=\sum_{i=1}^{N}\left(Y-Y_{i}\right)$

$\mathrm{SSE}=\sum_{i=1}^{N}\left(Y-Y_{i}\right)^{2}$,

where $N$ is the number of output data, $Y$ is the model output and $Y_{i}$ is the real output. Results indicated that using a combination of linear functions for activity and transferring of this artificial neural network, in addition to the lowest error, has also provided a more coherent response. In other combination of functions, although in some cases, error responses were low; however, often the answers provided the dispersion. It should be acknowledged that TSI behavior of Dez Dam reservoir, based on initial structure, follows linear transfer and activity functions. In artificial neural networks, coefficient of determination between real outputs (optional) and the simulated outputs by the network can be considered a criterion for measuring the learning limit and network performance (Chegini 2009). Hence, with estimation of coefficient of determination between real outputs and modeled output in the different structures of the neural network with linear functions, the best structure in terms of number of hidden layer cells with the highest coefficient of determination is a network with 25 neurons of hidden layer with $R^{2}=0.8377$ (Fig. 5).

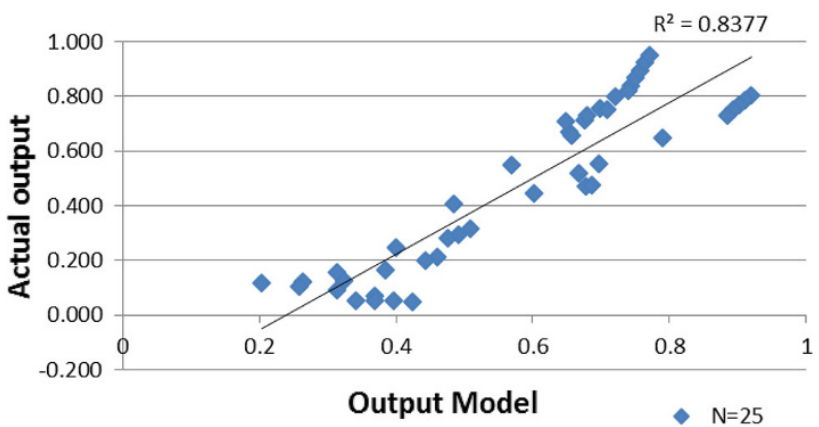

Fig. 5 Coefficient of determination of real output and modeled output in neural network with linear activity function, linear transfer function and 25 cells of hidden layer

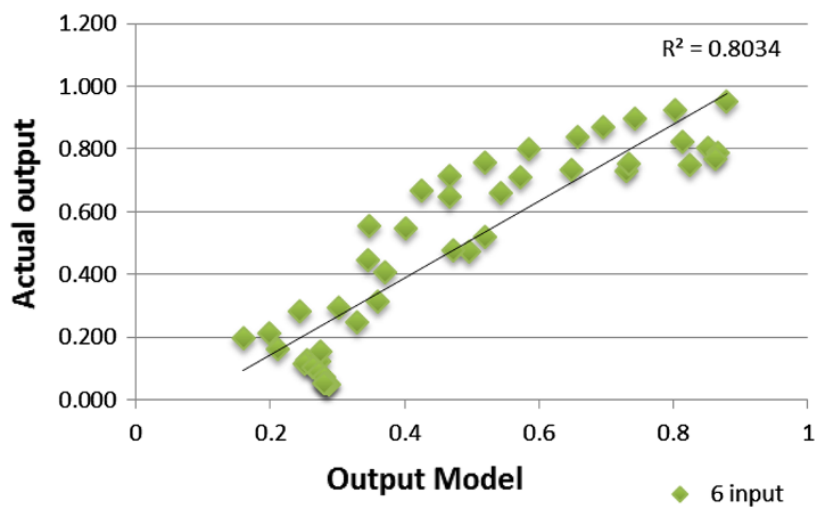

Fig. 6 Coefficient of determination of real output and modeled output in neural network with 6 input parameters, linear activity function, linear transfer function and 25 cells of hidden layer

At this stage, a question may appear whether or not changing the number of input parameters can be involved in the response improvement provided by the network. To answer the question, we follow up with changes in input data. The most likely hypothesis is using TSI empirical formula and eliminating parameters SD and DO that seems to lead us to more accurate answer. As it can be seen in Fig. 6, changing the input data of coefficient of determination will cause the output data to be reduced; therefore, artificial neural network is found to be far away from the real answer.

Sensitivity analysis has been done to identify the most effective input parameter in the TSI analysis. In general, this process in neural networks is done by removing or adding methods of the analyzed parameter in the final network (Memarianfard 2009). Based on this, adding or removing any parameter corresponds to the greatest increase or decrease, respectively, in the coefficient of determination which would be considered as the most sensitive input parameter of neural networks. Therefore, in the neural network revised for the trophic state analysis of Dez Dam reservoir, one parameter out of eight input parameters was removed and the network was trained and 


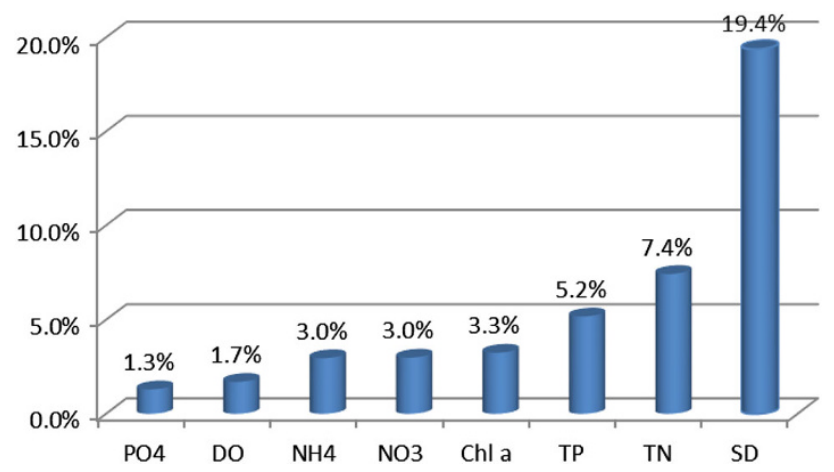

Fig. 7 Correlation amount of final response of artificial neural network to input parameters

tested again. Coefficient of determination analysis of the obtained results correlation selective network output indicates that depth, total nitrogen, total phosphorus and chlorophyll $a$ are the most sensitive input parameters of this network, respectively. In contrast, phosphate, dissolved oxygen, ammonia and nitrate, have low sensitivity, respectively (Fig. 7).

Understanding the eutrophication state of dam reservoirs would help to determine the quality enforcement priorities. In the Dez Dam reservoir, considering the eutrophication state especially in warm seasons, it is necessary to control the pollutions, which enter the watershed, and reduction of nutrients entering the reservoir. Collection and treatment of sanitary and industrial wastewaters, drainage control of agricultural lands and performance of watershed management projects are some of the approaches that could be beneficial in this regard. Following scenarios have been studied in order to find the effects of eliminating specified percentage of the input nutrients, which lead to the controlling strategies in the watershed, on the TSI; also, to see whether the artificial neural network can express these changes:
- First scenario: management strategies of pollution control in the watershed and nutrients reduction entering the Dez Dam reservoir-this scenario has been tested with values of 25 and $50 \%$.

- Second scenario: no management strategies in the watershed area. Therefore, nutrients entering the Dez Dam reservoir would increase and result in agricultural, industry, etc., development at upstream-this scenario has been tested with values of 25 and $50 \%$.

Therefore, neural network was trained and simulated again after changing the input data. The results are shown in Figs. 8 and 9.

The results in these figures show that ANN can model the effect of increment and decrement of nutrients on TSI. Accordingly, $50 \%$ increment of TSI in a short time causes a mesotrophic condition. Most of the time, the Dez Dam reservoir is in eutrophic condition.

\section{Conclusions}

Based on the results from estimation of modified Carlson TSI, Dez Dam reservoir is considered to be eutrophic in the early July to mid-November and would be mesotrophic by decrease in temperature. Therefore, a decrease in water quality of the Dam reservoir during the warm seasons is expectable. Progressive artificial neural network with 8 input parameters, a hidden layer consisting of 25 neurons and combination of activity and linear transfer function, has created the most appropriate structure for analysis of TSI behavior of Dez Dam reservoir. Output data of this structure have coefficient of determination of 0.8377 with real data. Editing neural network structure shows the most sensitivity to the depth changes, total nitrogen, total phosphorus and the chlorophyll $a$, respectively. Therefore,
Fig. 8 Trophic state index simulation of Dez Dam reservoir with nutrients decrease

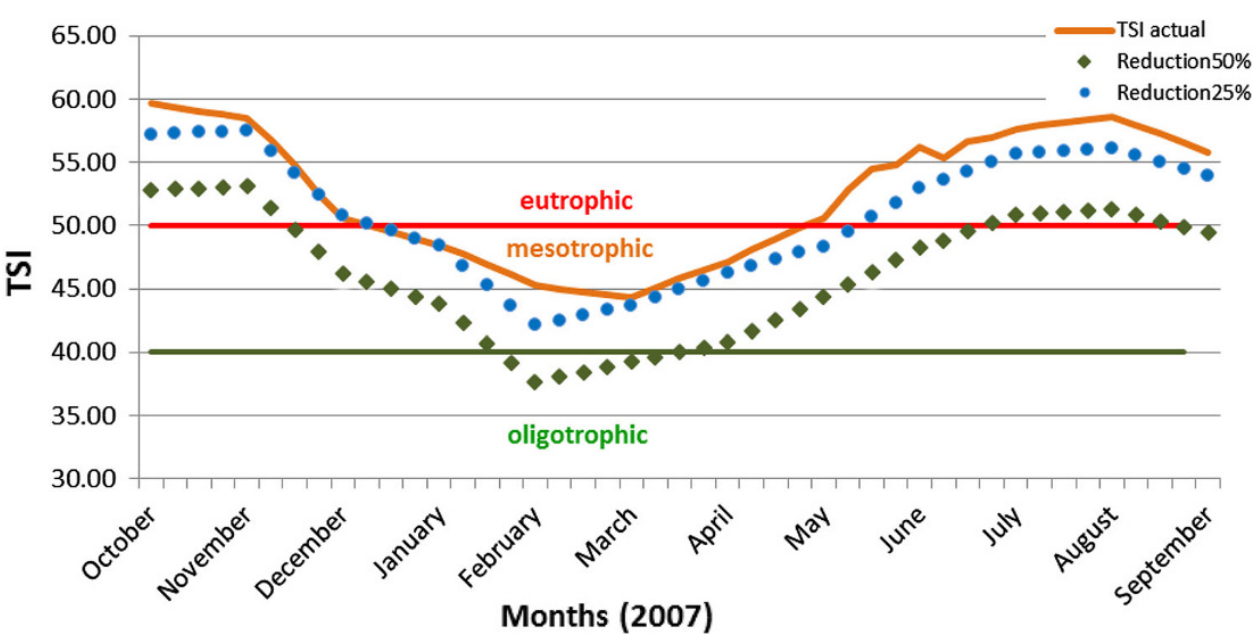


Fig. 9 Trophic state index simulation of Dez Dam reservoir with nutrients increase

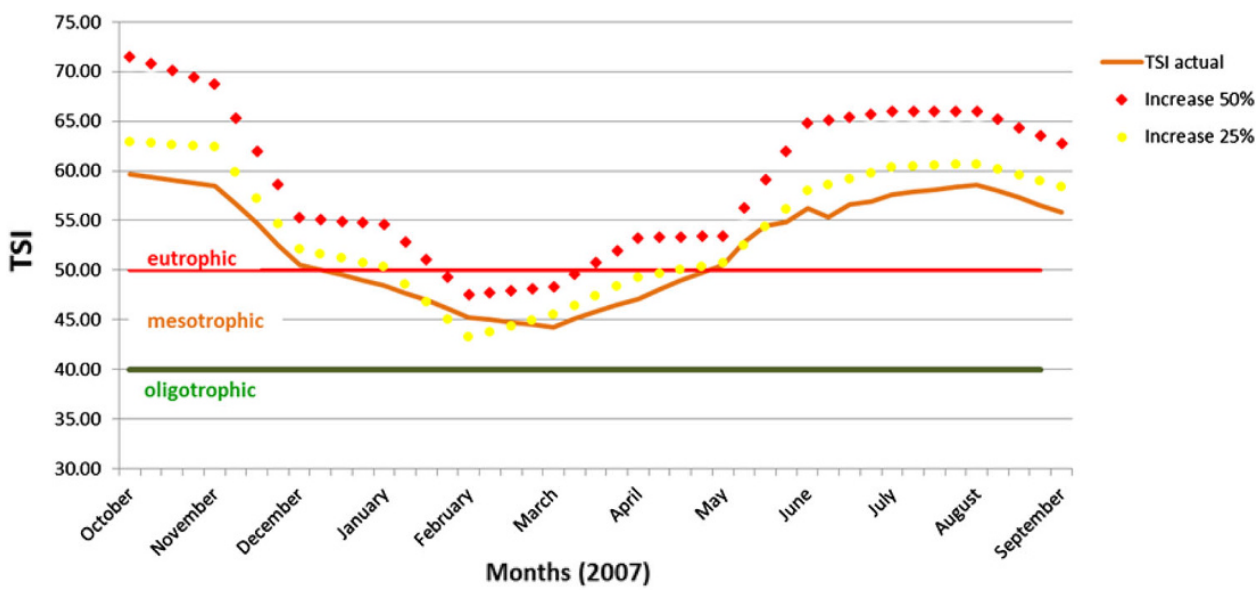

these parameters are the most sensitive input parameters of neural network. In contrast, phosphate, dissolved oxygen, ammonia and nitrate, respectively, have low sensitivity.

According to the results of sensitivity analysis, it should be mentioned that the existing empirical indices have correctly introduced parameters of depth, total nitrogen, total phosphorus and the chlorophyll $a$ as the most important parameters affecting the TSI analysis. However, adding parameters such as dissolved oxygen, phosphate, nitrate and ammonia can help to improve the accuracy of estimations. Artificial neural networks can accurately predict the decrease scenarios or the increase in input nutrients. Moreover, it could enhance understanding the process of TSI changes. Based on this, in case of performing an appropriate pollution control management program, water quality of dam reservoir could be improved, except for a short period in summer in which a poor atrophic condition would occur. Otherwise, having no quality management program would cause a reduction in water quality and an increase in eutrophication state.

Open Access This article is distributed under the terms of the Creative Commons Attribution License which permits any use, distribution, and reproduction in any medium, provided the original author(s) and the source are credited.

\section{References}

Aizaki M, Iwakuma T, Takamura N (1981) Application of modified Carlson's trophic state index to Japanese lakes and its relationship to other parameters related to trophic state. Res Rep Nat Inst Environ Stud 23:13-31

Borchardt MA (1996) Factors affecting benthic algae: nutrients. In: Stevenson RJ, Bothwell ML, Lowe RL (eds) Algal ecology: freshwater benthic ecosystems. Academic Press, San Diego, pp 184-217

Boyle TP, Smillie GM, Anderson JD (1990) A sensitivity analysis of nine diversity and seven similarity indices. Res J WPCF 62:749-762
Carlson RE (1977) Atrophic state index for lakes. Limnol Oceanogr 22(2):361-369

Caudill M, Butler C (1992) Understanding neural networks basic networks. MIT Press, Cambridge

Chapra SC (1983) Engineering approaches for lake management. Data analysis and empirical modeling. Butterworth Publishers, Boston, p 340

Chegini A (2009) MATLAB tools box, Naghos Publishing

Codd GA, Morrison LF, Metcalf JS (2005) Cyanobacterial toxins: risk management for health protection. Toxicol Appl Pharm 203:264-272

Cruzado A (1987) Eutrophication in the pelagic environment and its assessment. Eutrophication in the Mediterranean Sea: receiving capacity and monitoring of long term effects. UNESCO Rep Mar Sci 49:57-66

Cüneyt Karul A (1999) Neural network models as a management tool in lakes. Hydrobiology 408:139-144

Cüneyt Karul A (2000) Case studies on the use of neural networks in eutrophication modeling. Ecol Model 134:145-152

Danilov R, Ekelund NGA (1999) The efficiency of seven diversity and one similarity indices based on phytoplankton data for assessing the level of eutrophication in lakes in central Sweden. Sci Total Environ 234:15-23

Haykin S (1999) Neural networks: a comprehensive foundation. Prentice-Hall, New Jersey

Ichiyanagi K (1995) An artificial neural network to predict river flow rate into a dam for a hydro-power plant, neural networks. In: Proceedings of IEEE International Conference

(1996) Integrated Water Quality Assessment for Florida: 1996 305(b) Report and 303(d) List Update October 2008-Florida Department of Environmental Protection

(2008) Integrated Water Quality Assessment for Florida: 2008 305(b) Report and 303(d) List Update October 2008-Florida Department of Environmental Protection

Janjua MY, Ahmad T, Akhtar N (2009) Limnology and trophic status of Shahpur Dam reservoir, Pakistan. J Animal Plant Sci 19(4)

Jan-Tai Kuoa (2007) Using artificial neural network for reservoir eutrophication prediction ecological modeling 200

Jin X, Liu H, Tu Q, Zhang Z, Zhu X (1990) Eutrophication of lakes in China. China Environmental Sciences Press, Beijing, p 614

Johns W (1998) Indiana trophic state index. Lakes Water Quality Assessment Program, Indiana Department of Environmental Management, Indianapolis, Indiana

Kratzer CR, Brezonik PL (1981) A carlson-type trophic state index for nitrogen in florida lakes. J Am Water Resour Assoc 17(4):713-715 
Lee JHW, Huanga Y, Dickmanb M, Jayawardenaa AW (2003) Neural network modeling of coastal algal blooms. Ecol Model 159:179-201

Jothiprakash V, Garg V, S.M.ASCE-J (2009) Reservoir sedimentation estimation using artificial neural network. Hydrol Eng 14:1035. doi:10.1061/(ASCE)HE.1943-5584.0000075

Kiersztyn B (2002) Ectoenzyme activity: useful parameters for characterizing the trophic conditions of lakes. Environ Stud 11(4):367-373

Kosten S (2012) Warmer climates boost cyanobacterial dominance in shallow lakes. Global Change Biol 18:118-126

Mandaville SM (2000) Limnology-eutrophication and chemistry, carrying capacities, loadings, benthic ecology, and comparative data. Soil and Water Conservation Society of Metro Halifax, Halifax

Mandaville SM (2005) Trophic state and data evaluation methodology. Environmental Management Services, Dartmouth

Mark W, Friedrich R, Craig C, Myriam B (2001) Predicting eutrophication effects in the Burrinjuck Reservoir (Australia) by means of the deterministic model SALMO and the recurrent neural network model ANNA. Ecol Model 146:97-113

McCulloch WS, Pitts W (1943) A logical calculus of the ideas imminent in nervous activity. Bull Math Biophys 5:115-133

Memarianfard M (2009) Comparison of artificial neural network models and transitional regression functions for predicting cation exchange capacity of Chahar Mahal. J Water Soil (Sci Ind and Agric) 23(4):90-99

Moshanir Consulting Engineering Company (2007) environmental impact assessment Dez Dam second powerhouse

Muhittin Aslan A (2008) Modeling the water quality of Lake EMIR using artificial neural networks (ANN) and adaptive neuro fuzzy inference system (ANFIS)
Nutrient and Dissolved Oxygen TMDLs for Northgate Dam in Burke County, North Dakota (2006) North Dakota Department of Health Division of Water Quality

Porcella DB, Peterson SA, Larsen DP (1980) Index to evaluate lake restoration. J Environ Eng Div ASCE 106(EE6):1151-1169

Rumelhart DE, Hinton GE, Williams RJ (1986) Learning internal representations by error propagation. In: Rumelhart DE, McClelland JL (eds) Parallel distributed processing. MIT Press, Cambridge, pp 318-362

Ryding S, Rast W (1989) The control of eutrophication of lakes and reservoirs. Parthenon Publishing Co., UNESCO, Paris

Salmasi F (2010) An artificial neural network (ANN) for hydraulics of flows on stepped chutes. Eur J Sci Res 45(3). ISSN:1450-216X

Sharma MP et al (2010) Assessment of trophic state of lakes: a case of Mansi Ganga lake in India-Hydro Nepal issue no. 6

Swanson ER (1998) Trophic state index revisited. Lake Line 18(4): $18-20$

Therriault JC, Platt T (1978) Spatial heterogeneity of phytoplankton biomass and related factors in the near-surface waters of an exposed coastal environment. Limnol Oceanogr 23:888-899

Walker WW (1979) Use of hypolimnetic oxygen depletion rate as a trophic state index for lakes. Water Res 15(6):1463-1470

Xu FL (2008) Trophic classification for lakes. In: Jørgensen SE, Fath BD (eds) Ecological indicators. Vol. 5 of encyclopedia of ecology, 5th edn., pp 3594-3601

$\mathrm{Xu}$ FL (2011) The variations of exergies and structural exergies along eutrophication gradients in Chinese and Italian lakes. Ecol Model 222(2011):337-350

Yoshimi H (1987) Simultaneous construction of single-parameter and multiparameter trophic state indices. Water Res 21(12):1505-1611 